\title{
HEALTH PROTECTION OF PRISONERS IN THE REPUBLIC OF MACEDONIA
}

\section{Tanja Jovanovska ${ }^{1}$, Biljana Kocić ${ }^{2}$ Viktorija Proanovska-Stojčevska $^{3}$, Domnika Rajchanovska $^{4}$, Izabela Filov ${ }^{5}$, Biljana Bogdanova ${ }^{6}$}

\begin{abstract}
INTRODUCTION: Prisoners' health is one of the major challenges of public health systems because of prisoners' greater care needs due to the poor economic conditions connected to the numerous risks and higher morbidity and mortality related to incarceration. Malnutrition, infectious diseases, overcrowding, strict custodial physical infrastructure, and limited access to basic health services, among other factors, contribute to a worsening of the physical and mental health of prisoners
\end{abstract}

OBJECTIVES: This study aimed to ascertain leading health problems, care needs, and the degree of health protection used in the prison population of the Republic of Macedonia.

METHODS: The research is a cross-sectional study of the prison population, composed of 550 prisoners, with 100 situated in Bitola's prison, 100 in the prison of Prilep, 50 women imprisoned in the women's section of the correctional institution, Idrizovo, and another 300 prisoners from Idrizovo.

RESULTS: The most important reasons for causing illness amount examinees were the conditions in prison (as considered by $73.0 \%$ of respondents), drug use (by $50.4 \%$ of respondents), stress (by $45.6 \%$ of respondents), and improper nutrition (by $43.6 \%$ of respondents).

CONCLUSION: Findings suggest a poor health status for prisoners due to specific problems and care needs.

UDC Classification: 614.4 DOI: http://dx.doi.org/10.12955/cbup.v4.829

Keywords: prisoners; health care; health services; infectious diseases; chronic diseases.

\section{Introduction}

Prisoners' health is an important challenge of public health systems because of the specific needs and poor socio-economic conditions connected to numerous risks and higher morbidity and mortality arising from incarceration (Galea \& Vlahov, 2002; Butler, Kariminia, Levy \& Murphy, 2004; Greenberg \& Rosenheck, 2008). There is strong evidence indicating prisoners have higher rates of mental and physical disorders and a higher risk of suicide than the general population (Pratt, Piper, Appleby, Webb \& Shaw, 2006; Watson, Stimpson \& Hostick, 2004). Prisoners also have higher degrees of anxiety, sleeping problems, and depression than the general population (Condon, Hek \& Harris, 2007). Comorbidity of mental health problems and disorders because of drug abuse are also more frequent (Norwegian Ministry of Justice and the Police, 2008; Sirdifield, Gojkovic, Brooker \& Ferriter, 2009). Additionally, prisoners are under a higher risk of death after leaving prison, mainly during the first fortnight, with the greatest risk factors for previous prisoners being drug overdose, cardiovascular disease, murders, and suicides (Binswanger et al., 2007; Rosen, Schoenbach \& Wohl, 2008). Infectious diseases such as HIV and Hepatitis B and C infections are especially prevalent. Asthma and chronic pulmonary disease are among the more frequent physical disorders (Kjelsberg \& Hartvig, 2005). In spite of higher morbidity, it is known that prisoners abuse health services (Howerton et al., 2007; Skogstad, Deane \& Spicer, 2006) and disregard health services when they are not in prison. They are not sufficiently aware of services available to all (Mitchell \& Latchford, 2010). Persons with an inferior health status are generally represented among those who have contact with the criminal legal system (Freudenberg, 2002). Prisons are actually a concentrative mechanism for relatively unhealthy persons, partly because of behaviors and structural factors that lead to poor health

\footnotetext{
${ }^{1}$ Tanja Jovanovska, University St. Kliment Ohridski, Medical College, Bitola, Republic of Macedonia, tanjajovanovska42@gmail.com

${ }^{2}$ Biljana Kocić, University of Niš, Medical Faculty, Niš, Republic of Serbia

${ }^{3}$ Viktorija Proanovska-Stojčevska, University St. Kliment Ohridski, Medical College, Bitola, Republic of Macedonia

${ }^{4}$ Domnika Rajchanovska, University St. Kliment Ohridski, Medical College, Bitola, Republic of Macedonia

${ }^{5}$ Izabela Filov, University St. Kliment Ohridski, Medical College, Bitola, Republic of Macedonia

${ }^{6}$ Biljana Bogdanova, University St. Kliment Ohridski, Medical College, Bitola, Republic of Macedonia
} 
(e.g. drug and alcohol use). Prisons facilitate wider unpleasant conditions through its culture and these normalize harmful behaviors that affect health, such as smoking, drug injecting, and violence. In many environments, prisons cause exacerbation of existing health conditions in prisoners who become less mental and physically healthy than on entering the prison (Smith, 2002; National Commission on Correctional Health Care, 2002). Malnutrition, infectious diseases, over amassment, severe custodian, and physical infrastructure contribute to worsening of physical and mental health status of prisoners (Golembeski \& Fullilove, 2008; Awofeso, 2005). Extreme impact from worsening health conditions is also reflected in the higher number of death cases while under institutional control, and this is a phenomenon that is closely related to worsening of prisoner mental and physical health.

The aim of this paper is to establish the leading health problems, health needs, and degree of utilization of health protection in the prison population of the Republic of Macedonia.

\section{Material and Methods}

The research is a cross-sectional study of prison population, composed of 550 prisoners, with 100 situated in Bitola's prison, 100 from the prison of Prilep (the entire prison population), 50 women from the women's section of the correctional institution of Idrizovo, and another 300 prisoners from Idrizovo.

Inclusive criteria were: age (18 years and above) and the duration of stay within the correctional institution (minimum 3 months). Exclusive criteria were: age (less than 18 years) and staying in the institution with institutional sanctions less than 3 months.

The research instrument involved an authorized questionnaire for each gender. The questionnaire was composed of three parts for both genders. The first part contained questions of general demographic characteristics and socio-economic status (11 questions). The second part contained questions about health assessment and knowledge about health ( 8 questions). The third part contained questions about utilization of health service in prisons (7 questions). The questionnaire for females contained one more part, which was related to health protection specifics for women (7 questions).

The data were collected from the questionnaires completed by the prisoners after they received introductory explanations. Participation in the study was voluntary for examinees and all could freely cancel their participation in the study without negative consequences.

The statistical elaboration and data analyzes involved appropriate methods of correlation, proportion, and statistical rate series on qualitative results, with measures of dispersion (standard deviation and standard error) used in analyzing quantitative data. Statistical signification of differences in the series with both qualitative and quantitative data was confirmed after testing hypotheses by Pearson's chisquared test, using $\mathrm{p}<0.05$. The results are presented in graphs and tables, and tests were performed using the statistical package for social sciences (SPSS), version 14.

Ethics

The study summary, questionnaires of informative agreement, and questionnaires used during the research were approved by the Ethics Commission of Medical Investigation at the medical faculty in Skopje and the Institution of Performing Sanctions at the Ministry of Judicature in the Republic of Macedonia.

\section{Results}

From 550 examinees, $54.50 \%$ males were imprisoned in Idrizovo near Skopje, $18.20 \%$ of males were in Prilep's prison, $18.20 \%$ in Bitola's prison, and $9.10 \%$ of females at the women's prison in Idrizovo. The average age of male prisoners was $31.9 \pm 8$ years and that of female prisoners was $35.5 \pm 11.3$ years; most prisoners of both genders had limited education (57.6\% of males and $48.0 \%$ of females). Secondary education degrees were found among $37.6 \%$ of males and $44 \%$ of females. Higher education with experience was found in $4.8 \%$ of males and $8 \%$ of females. Most of the prisoners were unemployed (56.2\% of males and $48.0 \%$ of females), and $22.4 \%$ of males and $28 \%$ of females were registered as employed prior to imprisonment. Self-employment was found in $20 \%$ of males and $16 \%$ of females. The difference in reponses between unemployed and other modalities for each gender was found to be statistically significant at $\mathrm{p}<0.05$. The average duration of punishment for male 
examinees was $60.4 \pm 53.5$ months, but ranged from 3 to 360 months. The average duration of punishment for female examinees was $53.6 \pm 46.9$, but ranged from 6 to 240 months.

Table 1 presents the distribution of examinees according to gender and registered medical condition. For male prisoners, the main registered conditions were anxiety $(32.8 \%)$, hypertension $(23.8 \%)$, chronic bronchitis $(15.0 \%)$, hepatitis B and C (15.0\%), followed by kidney disease (14.2\%), sexual disease (7.8\%), diabetes (3.6\%), infarction (3.2\%), and other conditions represented in less than $2.4 \%$ of examinees.

Table 1: Distribution of examinees according to gender in terms of a registered medical condition (in relation to that whether an illness is discovered)

\begin{tabular}{|l|c|c|c|c|c|c|c|c|}
\hline \multirow{2}{*}{ Disease } & \multicolumn{4}{|c|}{ Males } & \multicolumn{4}{c|}{ Females } \\
\cline { 2 - 11 } & \multicolumn{2}{|c|}{ No } & \multicolumn{2}{c|}{ Yes } & \multicolumn{3}{c|}{ No } & \multicolumn{2}{c|}{ Yes } \\
\cline { 2 - 10 } & $\mathbf{N}$ & $\mathbf{\%}$ & $\mathbf{N}$ & $\mathbf{\%}$ & $\mathbf{N}$ & $\mathbf{\%}$ & $\mathbf{N}$ & \% \\
\hline Hypertension & 381 & 76.2 & 119 & 23.8 & 32 & 64.0 & 18 & 36.0 \\
\hline Diabetes & 482 & 96.4 & 18 & 3.6 & 49 & 98.0 & 1 & 2.0 \\
\hline Infarction & 484 & 96.8 & 16 & 3.2 & 45 & 90.0 & 5 & 10.0 \\
\hline Cerebrovascular insult & 495 & 99.0 & 5 & 1.0 & 49 & 98.0 & 1 & 2.0 \\
\hline Chronic bronchitis (asthma) & 425 & 85.0 & 75 & 15.0 & 39 & 78.0 & 11 & 22.0 \\
\hline Kidney disease & 429 & 85.8 & 71 & 14.2 & 39 & 78.0 & 11 & 22.0 \\
\hline $\begin{array}{l}\text { Chronic nervousness } \\
\text { (anxiety) }\end{array}$ & 336 & 67.2 & 164 & 32.8 & 26 & 52.0 & 24 & 48.0 \\
\hline Cancer & 492 & 98.4 & 8 & 1.6 & 49 & 98.0 & 1 & 2.0 \\
\hline Tuberculosis & 488 & 97.6 & 12 & 2.4 & 49 & 98.0 & 1 & 2.0 \\
\hline Hepatitis B, Hepatitis C & 425 & 85.0 & 75 & 15.0 & 43 & 86.0 & 7 & 14.0 \\
\hline Sexual disease & 461 & 92.2 & 39 & 7.8 & 42 & 84.0 & 8 & 16.0 \\
\hline Source: Author & \multicolumn{9}{|c|}{} & & & & \\
\hline
\end{tabular}

The majority of male prison examinees $(73.0 \%)$ considered that the most important cause for developing a medical condition was prison conditions; while $50.4 \%$ considered taking drugs, $45.6 \%$ stress, and $43.6 \%$ malnutrition as the reason for such. Female examinees considered the three most important causes for developing a medical condition were anxiety (84.0\% of respondents), malnutrition (74.0\% of respondents), and prison conditions ( $74.0 \%$ of respondents; Table 2 ).

Most male examinees (44.8\%) considered health services as available when they needed them, but not always; $31.8 \%$ considered the services as always available; while only $23.4 \%$ considered these to be unavailable. Most female examinees $(66.0 \%)$ considered health services to be available when needed, but not always; $20.0 \%$ considered them as always being available; while $14 \%$ considered them unavailable. The difference among responses for both gender cases was statistically significant at $\mathrm{p}<$ 0.05 (chi square $=2.09 ; \mathrm{df}=1 ; 95 \%$ Confidence Interval $=9.003-13.841)$, with a weak correlation, phi coefficient $=0.2$ (Table 3$)$.

As for when the dentist was needed, $38.6 \%$ of male examinees considered this service to be unavailable; $38.6 \%$ as available when needed but not always; while $22.8 \%$ considered it as always available. Female prison examinees $(62.0 \%)$ considered the dentist as being available when needed, but not always; $26.0 \%$ as always available; but $12 \%$ considered this service as unavailable. The difference among responses for both gender cases was statistically significant at $\mathrm{p}<0.05$ (chi square $=9.112 ; \mathrm{df}=1 ; 95 \%$ Confidence Interval $=25.013-65.112$ ), with a weak correlation, $\mathrm{phi}=0.23$ coefficient.

In terms of whether female examinees had seen an available gynecologist during their imprisonment, $56.0 \%$ answered yes but not always, while $42 \%$ answered always. The results showed $42.0 \%$ of cases had a Papanicolau test more than 12 months ago; $18.0 \%$ had one within the last 12 months; and $30.0 \%$ could not remember when their last test was done. Of the examinees, $52.0 \%$ had never had a mammography, $20.0 \%$ had never heard of it, and $14.0 \%$ had undergone one over 12 months ago. 
The data obtained about general health conditions, as a result of self-assessment among prisoners in the Republic of Macedonia, showed $63.2 \%$ of male examinees considered their health to be "good", while $36.8 \%$ considered it "not good". The difference among responses was statistically significant at $\mathrm{p}=0.0000$. The results also showed $46 \%$ of female examinees considered their health as good, while $54.0 \%$ considered it to be not good. The difference among responses in this respect was not statistically significant, with a $p>0.05$. Compared to 12 months ago, $74.0 \%$ of male and $58.2 \%$ of female examinees considered their health to be worse. Examinees from both genders occasionally followed themes connected to health, generally on TV, radio, and newspapers $(47 \%, 46.4 \%, 36.6 \%$, and $54.0 \%, 34.0 \%)$, but for many, brochures, posters and organized lectures $(56.2 \%, 67.6 \%$ and $52 \%$ and $68 \%$ ) were not available. Examinees' opinions from both genders concerning some inference to health were divided among those who consider nutrition, physical activity, smoking, drinking alcohol, drug addiction, and risky sexual behavior as very important, and those who were not aware or had no opinion of such.

Table 2. Distribution of examinees according to gender in relation to opinions on the three most important reasons for developing a medical condition (becoming ill in prison

\begin{tabular}{|l|c|c|c|c|}
\hline \multirow{2}{*}{ Reasons } & \multicolumn{2}{|c|}{ Males } & \multicolumn{2}{c|}{ Females } \\
\cline { 2 - 5 } & $\mathbf{N}$ & $\mathbf{\%}$ & $\mathbf{N}$ & $\mathbf{\%}$ \\
\hline Malnutrition & 218 & 43.6 & 37 & 74.0 \\
\hline Anxiety & 228 & 45.6 & 42 & 84.0 \\
\hline Prison conditions & 365 & 73.0 & 37 & 74.0 \\
\hline Hard work & 18 & 3.6 & 6 & 12.0 \\
\hline Corporal punishment & 61 & 12.2 & 3 & 6.0 \\
\hline Smoking & 61 & 12.2 & 2 & 4.0 \\
\hline Drug abuse & 252 & 50.4 & 7 & 14.0 \\
\hline Alcohol consumption & 21 & 4.2 & & \\
\hline Risky sex behaviors & 89 & 17.8 & 2 & 4.0 \\
\hline Insufficient health protection & 149 & 29.8 & 11 & 22.0 \\
\hline Other & 28 & 5.6 & 3 & 6.0 \\
\hline Source: Author & \multicolumn{5}{|l}{} \\
\hline
\end{tabular}

Table 3. Distribution of examinees according to gender in relation to whether they have access to medical staff as needed (differences significant at $\mathrm{p}<0.05 ; \chi^{2}=2.09 ; \mathrm{df}=1 ; 95 \% \mathrm{CI}=9.003$ 13.841; Phi coefficient $=0.2$ )

\begin{tabular}{|l|c|c|c|c|}
\hline \multirow{2}{*}{ Access } & \multicolumn{2}{|c|}{ Males } & \multicolumn{2}{c|}{ Females } \\
\cline { 2 - 5 } & $\mathbf{N}$ & $\mathbf{\%}$ & $\mathbf{N}$ & $\mathbf{\%}$ \\
\hline No & 117 & 23.4 & 7 & 14.0 \\
\hline Yes, but not always & 224 & 44.8 & 33 & 66.0 \\
\hline Yes, always & 159 & 31.8 & 10 & 20.0 \\
\hline df: degrees of freedom; CI: confidence interval \\
\hline \multicolumn{4}{|l}{ Source: Author }
\end{tabular}

\section{Discussion}

In the previous study conducted among prisoners in both prisons of the Republic of Macedonia, regarding $\mathrm{HBV}, \mathrm{HCV}$, and $\mathrm{HIV}$, infections, the total prevalence of $\mathrm{HCV}$ was 0.20 ; total prevalence of HBV 0.17, and that of co-infection of HCV/ HBV was 0.07 (7\%), from 200 examinees (Jovanovska, Kocic, Prodanovska-Stojcevska \& Isjanovska, 2013). The research was conducted in three correctional facilitates in the Republic of Macedonia (Prison in Skopje, Prilep, and Bitola) and indicated significant higher prevalence of $\mathrm{HCV}$ and $\mathrm{HBV}$ infections in prisoners compared to general population (Jovanovska, Kocic \& Prodanovska-Stojcevska, 2014). 
The results of this cross-sectional study shows that the male prison examinees considered that the most important reason for disease emergence in prisons was the prison conditions ( $73.0 \%$ of respondents), followed by drug abuse (50.4\% of respondents), stress ( $45.6 \%$ of respondents), and then malnutrition (43.6\% of respondents), whereas $84.0 \%$ of female examinees considered stress and malnutrition equally as the cause, and $74.0 \%$ of females the prison conditions.

In terms of health protection, $44.8 \%$ of male examinees and 66.0 of females considered it as available when needed but not always; $31.8 \%$ of males and $20.0 \%$ of females considered it as always available, but $23.4 \%$ of males and $14 \%$ of females considered it as unavailable. One third of them considered that they had the doctor or other health staff available on the very same day they needed their service, while only $6.6 \%$ of males and $20 \%$ of females considered the doctor as being unavailable. The highest per cent of visits to the doctor were because of illness or medicinal requirements. Every fourth prisoner considered the dentist as always being available, but a higher per cent of male examinees (38.6\%) considered the dentist as being unavailable. As for the reproductive health of women, $98.0 \%$ of women had a positive opinion, i.e. the gynecologist was always available. Similar results were obtained during research in the Republic of Serbia (Research among populations at increased risk of HIV among people living with HIV, 2008). In Serbian prisons, every third prisoner confirmed that health protection was always available; every second prisoner attended the doctor because of illness; every fourth confirmed the dentist as always available; and more than one third of prisoners expressed satisfaction with health staff relations.

A study about self-assessment of health status and how the availability of health services in an example regarding prisoners in Italy was the first attempt of a health status self-assessment. Results confirmed former studies in that prisoners have their own opinion about poor health, high morbidity rate, and the frequency of visiting prison health services (Nobile, Flott, Nicotera, Pileggi \& Angelillo, 2011).

In the USA, half of newly admitted prisoners considered their health to be "good", "satisfactory ", or "bad" (Conklin, Lincoln \& Tuthill, 2000). However, in another study, none of the male prisoners considered their health as "bad", with $20 \%$ considering it as "satisfactory", and $53 \%$, as "good". Schnittker and John (2007) suggest that imprisonment might have a negative effect upon prisoners' health, especially after liberation, because while being under control they could not develop normal function and range in health, and also the time being in prison has a negative influence upon social integration, especially with their families.

The prison population in the United States has quadrupled in the last 25 years and now they have more prisoners per capita than in any other nation. Worldwide, imprisonment per 100 000, 30 is from India, to 75 from Norway, 119 from China, 148 from United Kingdom, 628 from Russia and 750 from the USA (King's College London, 2008). At the moment there are almost 2.3 million prisoners in the USA ( $1 \%$ of adults in USA), that must rely on prison guards for prison care (US Bureau of Justice Statistics, 2008). Even though the prisoners have constitutional rights for health care, according to the Eight Amendment about prohibition of "cruel and unusual punishment", occasional scandals and previous studies as well indicate that access of prisoners to health protection and a quality of that as well is very often deficient (Clemmitt, 2007; Wilper et al., 2009).

Quoting poor conditions in prison system of California, the Federal Court has taken down prison health care from state control (Moore, 2008). Still there are few representative findings about health and health care of American prisoners.

Prisoners have high rate of chronic internal conditions especially viral infections. Additionally, drug abuse and mental disorders are frequent among prisoners (Freudenberg, 2001; National Commission on Correctional Health Care, 2008). So far there is no any acknowledged study analyzing prevalence of general chronic conditions, access of internal and psychiatric care among prison population in total. As of that, the prevalence of selective chronic diseases, access to health and prior and post-prison psychiatric treatment of prison population in the United States is being demanded (Wilper et al., 2009).

Findings suggest that prisoners have a poor health status because of specific problems and care needs. Prison health services are almost equivalent to those provided in the community. 
But the prison system seldom provides programs aimed at health promotion or facilitating social reintegration, correction of risky behavior, and appropriate long term health effects of prisoners.

\section{Conclusion}

Health care for prisoners was surveyed in three penitentiary institutions in the Republic of Macedonia. The most common causes of diseases are: drug abuse, stress and improper diet (lack of nutrition). Consequently, the most frequent diseases are: chronic anxiety and high blood pressure. The coverage by preventive programs is low. Therefore, there is a need to promote standardization and ensure wide availability of diagnostic tests that allow early diagnosis. Adequate implementation and therapeutic procedures have been imposed.

\section{References}

Awofeso, N. (2005). Prisoner healthcare co-payment policy: a cost-cutting measure that might threaten inmates' health. Appl Health Econ Health Policy. 4:159-64. [PMID: 16309333]

Binswanger, I. A, Stern, M. F, Deyo, R. A, Heagerty, P. J, Cheadle, A., Elmore, J. G (2007). Release from prison - a high risk of death for former inmates. N Engl J Med. 356:157-65. DOI: 10.1056/NEJMsa064115 [PMID: 17215533]

Bureau of Justice Statistics (2008) [Internet]. US Department of Justice. Prison statistics, summary findings. Available from: http://www.ojp.usdoj.gov/bjs/prisons.htm.

Butler, T., Kariminia, A., Levy, M. \& Murphy, M. (2004). The self-reported health status of prisoners in New South Wales. Aust N Z J Public Health. 28:344-50. DOI: 10.1111/j.1467-842X.2004.tb00442 [PMID: 15704699]

Clemmitt, M. (2007) Prison health care. Congr Q.; 17:1-24.

Condon, L., Hek, G., Harris, F. (2007). A review of prison health and its implications for primary care nursing in England and Wales: the research evidence. J Clin Nurs. 16:1201-9 DOI: 10.1111/j.1365-2702.2007.01799.x [PMID: 17584337]

Conklin, T. J., Lincoln, T. \& Tuthill, R. W. (2000). Self-reported health and prior health behaviors of newly admitted correctional inmates. Am J Public Health. 90:1939-41. [PMID: 11111273]

Freudenberg, N. (2001). Jails, prisons, and the health of urban populations: a review of the impact of the correctional system on community health. J Urban Health. 78(2):214-35. DOI: 10.1093/jurban/78.2.214 [PMID: 11419576]

Freudenberg, N. (2002). Adverse effects of US jail and prison policies on the health and well-being of women of color. Am J Public Health. 92:1895-9. DOI: 10.2105/AJPH.92.12.1895 [PMID: 12453803]

Galea, S., \& Vlahov, D., (2002). Social determinants and the health of drug users: socioeconomic status, homelessness, and incarceration. Public Health Rep. 117:S135-45. DOI: 10.1186/1471-2458-11-529 [PMID: 12435837]

Golembeski, C., \& Fullilove, R. (2008). Criminal (in) justice in the city and its associated health consequences. Am J Public Health 98(Suppl 9):S185-90. [PMID: 18687612]

Greenberg, G. A., \& Rosenheck, R. A. (2008). Jail incarceration, homelessness, and mental health: a national study. Psychiatr Serv. 59:170-7. DOI: 10.1176/appi.ps.59.2.170 [PMID: 18245159]

Howerton, A., Byng, R., Campbell, J., Hess, D., Owens, C., \& Aitken, P. (2007). Understanding help seeking behaviour among male offenders: qualitative interview study, BMJ. 334(7588): 303. DOI: 10.1136/bmj.39059.594444.AE [PMID: 17223630]

Jovanovska, T., Kocic, B., Prodanovska-Stojcevska, V. \& Isjanovska, R. (2013). Prevalnce of HIV, Hepatitis B and C infections among inmates in prisons in the Republic of Macedonia. HealthMed journal, vol7, num1

Jovanovska, T., Kocic, B. \& Prodanovska-Stojcevska, V. (2014). Prevalence, attitudes and knowledge about HIV, HBV and HCV infections among inmates in prisons Prilep and Bitola-a pilot study. Collegium antropologicum 38(2):417-22

King's College London (2008). International Centre for Prison Studies. [Internet]. Entire world - prison population rates per 100,000 of the national population]. Available from: http://www.prisonstudies.org.

Kjelsberg, E., \& Hartvig, P. (2005). Can morbidity be inferred from prescription drug use? Results from a nation-wide prison population study. Eur J Epidemiol. 20:587-92. DOI: 10.1007/s10654-005-8156-9 [PMID: 16119431]

Mitchell, J., \& Latchford, G. (2010). Prisoner perspectives on mental health problems and help-seeking. J Forens Psychiatry Psychol. 21(5):773-88. DOI: 10.1080/14789949.2010.488697

Moore, S. (2008) [Internet]. Using muscle to improve health care for prisoners, 2007, New York Times. Available from: http://www.nytimes.com/2007/08/27/us/27prisons.html

National Commission on Correctional Health Care (2008) [Internet]. The Health Status of Soon-to-Be-Released Inmates, Vol. 1Available from: http://www.ncchc.org/pubs/pubs_stbr. vol1.html

National Commission on Correctional Health Care (2002). The health status of soon-to-be-released inmates: a report to Congress (volumes 1 and 2). Chicago: NCCHC

Nobile, C. G. A., Flott, D., Nicotera, G., Pileggi, C. \& Angelillo, I. F. (2011). Self-reported health status and access to health services in a sample of prisoners in Italy. BMC Public Health. 11:529. DOI: 10.1186/1471-2458-11-529 [PMID: 21726446]

Norwegian Ministry of Justice and the Police (2008). Report to the Storting no 37 Sentencing that works- less crime- safer society (Criminal re-establishment system report) Oslo: Norwegian Ministry of Justice and the Police. 
Pratt, D., Piper, M., Appleby, L., Webb, R. \& Shaw, J. (2006). Suicide in recently released prisoners: a population-based cohort study. Lancet. 368:119-23 DOI: 10.1016/S0140-6736(06)69002-8 [PMID: 16829295]

Research among populations at increased risk of HIV among people living with HIV (2008). The Ministry of health of Serbia

Rosen, D. L., Schoenbach, V. J. \& Wohl, D. A. (2008). All-cause and cause-specific mortality among men released from state prison, 1980-2005., Am J Public Health. 98:2278-84. DOI: 10.2105/AJPH.2007.121855 [PMID: 18923131]

Schnittker, J., \& John, A. (2007). Enduring stigma: the long-term effects of incarceration on health. J Health Soc Behav. 48:115-30. DOI: 10.1177/002214650704800202 [PMID: 17583269]

Sirdifield, C., Gojkovic, D., Brooker, C. \& Ferriter, M. (2009). A systematic review of research on the epidemiology of mental health disorders in prison populations: a summary of findings. J Forens Psychiatry Psychol. 20(S1):S78-101. DOI: $10.1080 / 14789940802594445$

Skogstad, P., Deane, F. P., \& Spicer, J. (2006). Social-cognitive determinants of help seeking for mental health problems among prison inmates. Crim Behav Ment Health. 16:43-59. DOI: 10.1002/cbm.54 [PMID: 16572490]

Smith, C. (2002). "Healthy prisons": a contradiction in terms? Howard J Crim Just. 39:339-53. DOI: 10.1111/14682311.00174

Watson, R., Stimpson, A., \& Hostick, T. (2004). Prison Health Care: a review of the literature. Int J Nurs Stud. 41:119-28. DOI: 10.1016/S0020-7489(03)00128-7 [PMID: 14725776].

Wilper, A. P., Woolhandler, S., Boyd, J. W., Lasser, K. E., McCormick, D., Bor, D. H., \& Himmelstein, D. U. (2009). The Health and Health Care of US Prisoners: Results of a Nationwide Survey. American Journal of Public Health, 99(4), 666672. http://doi.org/10.2105/AJPH.2008.144279 